\title{
Surto de intoxicação por sal em ovinos no estado do Pará ${ }^{1}$
}

\author{
Marcos D. Duarte², Pedro S. Bezerra Júnior², Danillo Henrique S. Lima², Henrique A. \\ Bomjardim $^{2}$, Carlos Magno C. Oliveira ${ }^{2}$, Natália da Silva e Silva ${ }^{3}$, Kelson C.F. Faial ${ }^{4}$ \\ e José Diomedes Barbosa ${ }^{2 *}$
}

\begin{abstract}
Duarte M.D., Bezerra Júnior P.S., Lima D.H.S., Bomjardim H.A., Oliveira C.M.C., Silva N.S., Faial K.C.F. \& Barbosa J.D. 2014. [Salt poisoning outbreak in sheep in the state of Pará.] Surto de intoxicação por sal em ovinos no estado do Pará. Pesquisa Veterinária Brasileira 34(11):1061-1068. Faculdade de Medicina Veterinária, Instituto de Medicina Veterinária, Campus de Castanhal, Universidade Federal do Pará, Rodovia BR-316 Km 61, Castanhal, PA 68741-740, Brazil. E-mail: diomedes@ufpa.br

This paper reports an outbreak of salt poisoning in sheep on a farm in the state of Pará, northern Brazil. Eight (1.46\%) animals were affected from a total of 545 sheep and four $(50 \%)$ of them died. The evaluation of the facilities and the handling indicated as predisposing factors excessive intake of the mineral supplement and water restriction. The main clinical signs were recumbency, decrease or absence of cutaneous sensibility, absence of auricular, palpebral and menace reflex, mydriasis, nystagmus, opisthotonus, spasticity of limbs, somnolence and stupor. Beside these signs bloat, diarrhea, tachypnea, tachycardia, dehydration and polyuria were observed. The course of the disease in animals that died ranged from two hours and a half to 48 hours. The medium of serum concentration of sodium and potassium of 31 sheep from the same group affected on samples collected during the outbreak revealed hypernatremia $(190 \mathrm{mEq} / \mathrm{l})$ and hyperkalemia $(8.2 \mathrm{mEq} / \mathrm{l})$. At necropsy, there was flattening of the cerebral gyri in one sheep; in this animal was found vacuolization of the neuropil in the cerebral cortex with moderate intensity in the intermediary and mild on the superficial layers, with increased perineural and perivascular spaces. In these areas there were markedly swollen nucleus of astrocytes with acute neuronal necrosis. The dosage of sodium in the brain of a sheep revealed a high value of 3.513ppm. The diagnosis was made based on the epidemiology, clinical signs, macro and microscopic lesions and in the dosages of sodium in serum and brain.
\end{abstract}

INDEX TERMS: Salt poisoning, sheep, sodium chloride, toxicosis, polioencephalomalacia.

RESUMO.- 0 presente trabalho relata um surto de intoxicação por sal em ovinos no Brasil, em uma propriedade no estado do Pará. De um total de 545 ovinos, oito animais adoeceram $(1,46 \%)$ e quatro destes morreram (50\%). A avaliação das instalações e do manejo indicaram como fato-

\footnotetext{
${ }^{1}$ Recebido em 10 de setembro de 2014.

Aceito para publicação em 24 de setembro de 2014.

${ }^{2}$ Faculdade de Medicina Veterinária, Instituto de Medicina Veterinária, Campus de Castanhal, Universidade Federal do Pará (UFPA), Rodovia BR316 Km 61, Castanhal, PA 68741-740, Brasil. *Autor para correspondência: diomedes@ufpa.br

${ }^{3}$ Universidade Federal Rural da Amazônia, Campus Paragominas. Rodovia PA-256, Bairro Nova Conquista, Paragominas, PA 68627-451, Brasil.

${ }^{4}$ Laboratório de Toxicologia "Edilson Brabo", Seção de Meio Ambiente (SAMAM), Instituto Evandro Chagas. Rodovia BR-316 Km 7, Levilândia, Ananindeua, PA 67030-000, Brasil.
}

res predisponentes a ingestão excessiva de mistura mineral e a restrição hídrica. Os principais sinais clínicos foram decúbito, diminuição ou ausência da sensibilidade cutânea, ausência dos reflexos de ameaça, palpebral e auricular, midríase, nistagmo, opistótono, espasticidade de membros, sonolência e estupor. Havia ainda, timpanismo, diarreia, taquipneia, taquicardia, desidratação e poliúria. A evolução do quadro clínico nos animais que morreram variou de duas horas e meia a 48 horas. As médias das concentrações séricas de sódio e de potássio de 31 ovinos do mesmo lote afetado pela intoxicação, em amostras colhidas durante o surto, revelaram hipernatremia $(190 \mathrm{mEq} / \mathrm{l})$ e hipercalemia $(8,2 \mathrm{mEq} / \mathrm{l})$. À necropsia, observou-se em um animal, achatamento das circunvoluções cerebrais. Microscopicamente, neste animal, evidenciou-se vacuolização moderada do neurópilo, particularmente nas lâminas intermediárias 
do córtex cerebral, com aumento dos espaços perineural e perivascular. Nessas áreas foram observados ainda, acentuada tumefação e edema dos astrócitos e necrose neuronal aguda. A dosagem de sódio no encéfalo de um ovino, revelou-se elevada com valor de $3.513 \mathrm{ppm}$. 0 diagnóstico foi realizado com base na epidemiologia, nos sinais clínicos, nas lesões macro e microscópicas e nas dosagens de sódio no soro e no encéfalo dos ovinos.

TERMOS DE INDEXAÇÃO: Intoxicação por sal, ovinos, cloreto de sódio, toxicose, polioencefalomalácia.

\section{INTRODUÇÃO}

O cloreto de sódio, que forma o sal comum, é o mais barato, mais palatável e o mais utilizado de todos os suplementos minerais. $\mathrm{O}$ seu valor na dieta de animais e de seres humanos foi reconhecido centenas de anos antes de serem estabelecidas as suas necessidades. 0 forte desejo por sal demonstrado por animais em pastejo foi percebido pelos primeiros criadores e o seu fornecimento regular foi considerado uma boa prática de manejo (Underwood \& Suttle 1999).

Entretanto, a partir da segunda metade do século XIX, a adição de salmoura à alimentação de suínos, foi associada à ocorrência de sinais neurológicos como vertigem, postura de cão-sentado, convulsões, contrações espasmódicas dos membros posteriores, andar com a cabeça baixa e pressão da cabeça contra a parede (Morton \& Simonds 1856).

Na primeira metade do século passado foram descritos os primeiros casos de intoxicação por sal em ruminantes, associados à ingestão de água de poço com alta salinidade, nos quais ocorreram sinais nervosos, digestórios e respiratórios (Ohman 1939, Moule 1945). Desde então, foram relatados vários casos de intoxicação em bovinos, associados à privação hídrica com consumo de quantidades adequadas (Lindley 1977) ou excessivas de sal (Trueman \& Clague 1978, Pearson \& Kallfelz 1982, Senturk \& Cihan 2004). A intoxicação também foi descrita devido ao consumo excessivo de suplementos contendo cloreto de sódio (Sandals 1978), à preparação incorreta de soluções eletrolíticas para hidratação oral, com consequente ingestão de soluções hipertônicas de sódio (Pringle \& Berthiaume 1988) e à ingestão de água e pastagens com elevado teor de sódio em áreas banhadas pela água do mar (Van Leween 1999). Porém, em pequenos ruminantes existem somente três relatos da intoxicação em ovinos e um em caprinos. Nos ovinos a doença foi descrita na Austrália (Moule 1945), na Nova Zelândia (Smith \& Fyfe 1971) e nos Estados Unidos da América (Scarratt et al. 1985); os dois primeiros casos foram associados à ingestão de águas com alta salinidade e o terceiro, ao consumo excessivo de suplemento mineral contendo 4\% de cloreto de sódio junto com privação hídrica. Em caprinos, o único relato da intoxicação foi feito na França (Buronfosse 1998) após o acesso acidental a grande quantidade de sal colocado em uma estrada para promover o descongelamento da neve.

No Brasil não existem relatos da intoxicação por sal em pequenos ruminantes. Em 1997, foi descrita uma doença neurológica em bovinos, observada em quatro proprieda- des rurais no Estado do Mato Grosso do Sul. Histologicamente todos os casos apresentaram necrose laminar de neurônios no córtex cerebral com infiltrados de eosinófilos nos espaços perivasculares e submeningeanos, além de infiltrados de eosinófilos no neurópilo. Em uma amostra de líquor colhida, a dosagem de sódio foi de $163 \mathrm{mEq} / \mathrm{l}$. Os autores afirmaram que os achados clínicos e histopatológicos, associados a altos níveis de sódio no líquor de um animal, eram semelhantes aos descritos na intoxicação por sal em suínos, mas que alguns aspectos epidemiológicos deveriam ser esclarecidos para o melhor entendimento da enfermidade (Lemos et al. 1997).

O diagnóstico e o estudo de surtos de intoxicação por sal em ruminantes no Brasil são imprescindíveis para o estabelecimento dos fatores epidemiológicos e do quadro clínico-patológico, associados à ocorrência desta enfermidade no país. A etiologia de doenças com quadro clínico neurológico, especialmente aquelas com sinais relativos ao cérebro e com lesões histológicas de polioencefalomalácia, muitas vezes permanece sem causa determinada, principalmente aquelas observadas em bovinos criados extensivamente. 0 objetivo deste trabalho é relatar os aspectos epidemiológicos, toxicológicos, clínicos e patológicos do primeiro surto de intoxicação por sal em ovinos diagnosticado no Brasil.

\section{MATERIAL E MÉTODOS}

Os dados referentes à epidemiologia e aos sinais clínicos foram obtidos em visitas à propriedade onde ocorreu a doença. Quatro animais foram submetidos à necropsia e fragmentos de órgãos das cavidades torácica e abdominal, bem como o encéfalo e a medula espinhal, foram coletados. 0 material coletado foi fixado em formol a $10 \%$, processado rotineiramente para a histopatologia e corado pela hematoxilina e eosina. No sistema nervoso foram colhidos fragmentos do córtex cerebral, cerebelo, hipocampo e mesencéfalo. Em dois animais, além desses locais, foram colhidos fragmentos do córtex occipital, frontal e parietal, cápsula interna e núcleos da base, tálamo e ponte.

Amostra de encéfalo de um animal com sinais clínicos da doença foi colhida e conservada sob congelamento $\left(-20^{\circ} \mathrm{C}\right)$ para dosagem de sódio ( $\mathrm{Na}$ ). Esta amostra foi seccionada em fatias finas utilizando-se navalhas esterilizadas de aço inoxidável, armazenada em tubos de polipropileno de $50 \mathrm{ml}$ do tipo falcon ${ }^{\circledR}$ e submetida ao processo de liofilização. Para este processo, a amostra foi congelada a $-70^{\circ} \mathrm{C}$, colocada em aparelho automatizado LIOTOP ${ }^{\circledR}$ (modelo L101), previamente ligado por um período de $10 \mathrm{minu}-$ tos a uma temperatura de $-55^{\circ} \mathrm{C}$, onde permaneceu por 12 horas até a secagem completa. Em seguida, a amostra foi triturada em gral com pistilo em MF. Para o processo de digestão, a amostra foi pesada entre 0,25 a 0,26 g e colocada em tubo de digestão de teflon. Em seguida foram adicionados $3 \mathrm{ml}$ de ácido nítrico com alto grau de pureza $\left(65 \% \mathrm{~m}_{\mathrm{v}} \mathrm{v}^{-1}\right), 1 \mathrm{ml}$ de ácido clorídrico $\left(30 \% \mathrm{~m} \cdot \mathrm{v}^{-1}\right)$ e $1 \mathrm{ml}$ de peróxido de hidrogênio $\left(30 \% \mathrm{~m} . \mathrm{v}^{-1}\right)$. A amostra ficou em repouso durante 2 horas para uma pré-digestão e foi colocada para digestão final, por 50 minutos, através do sistema fechado por radiação em microondas (MARSXpress, CEM Corp. Matthews, NC, USA) e aferidas ao volume final de $25 \mathrm{ml}$ em tubos de polipropileno do tipo falcon ${ }^{\circledR}$. $\mathrm{O}$ teor de $\mathrm{Na}$ foi quantificado por intermédio da técnica de espectrometria de emissão ótica com plasma induzido (ICP OES) no equipamento Vista-MPX CCD simultâneo, com visão axial (VARIAN. Inc) em sistema de amostragem automático (SPS - 5). O controle das condições operacionais do ICP OES foi realizado com o auxílio do software ICPExpert Vista. 
No período de ocorrência do surto foram colhidas amostras de sangue da veia jugular de 31 animais do mesmo lote dos animais que adoeceram. As amostras foram acondicionadas em tubos sem anticoagulante para extração de soro e posterior dosagem sérica de sódio. As concentrações de sódio e potássio no soro foram realizadas pelo método de fotometria de chama. As instalações foram medidas para avaliar a lotação, o fornecimento hídrico e de mistura mineral.

\section{RESULTADOS}

A doença ocorreu nos meses de junho a agosto de 2011, em uma propriedade localizada no município de Benevides, Pará. Na propriedade eram criados 545 ovinos das raças Santa Inês, Dorper, Texel e seus mestiços. Os adultos eram mantidos em regime de semi-confinamento com acesso a pastagens de Brachiaria humidicola e Panicum maximum cv. Massai e os jovens, em confinamento. Quando estabulados os ovinos eram mantidos em apriscos suspensos com piso ripado, em baias de 25 ou $50 \mathrm{~m}^{2}$, com uma taxa de lotação nas baias ao redor de $0,5 \mathrm{~m}^{2}$ por animal adulto. 0 fornecimento de água era feito em bebedouros com $51 \mathrm{~cm}$ de comprimento, $39 \mathrm{~cm}$ de largura e $14 \mathrm{~cm}$ de profundidade com fluxo de água regulado por boia. 0 acesso ao bebedouro era possível a dois animais por vez, através de duas aberturas na parede de cada baia (Fig.1). As baias menores possuíam um bebedouro e as maiores, dois. Os ovinos jovens recebiam como volumoso, capim elefante (Pennisetum

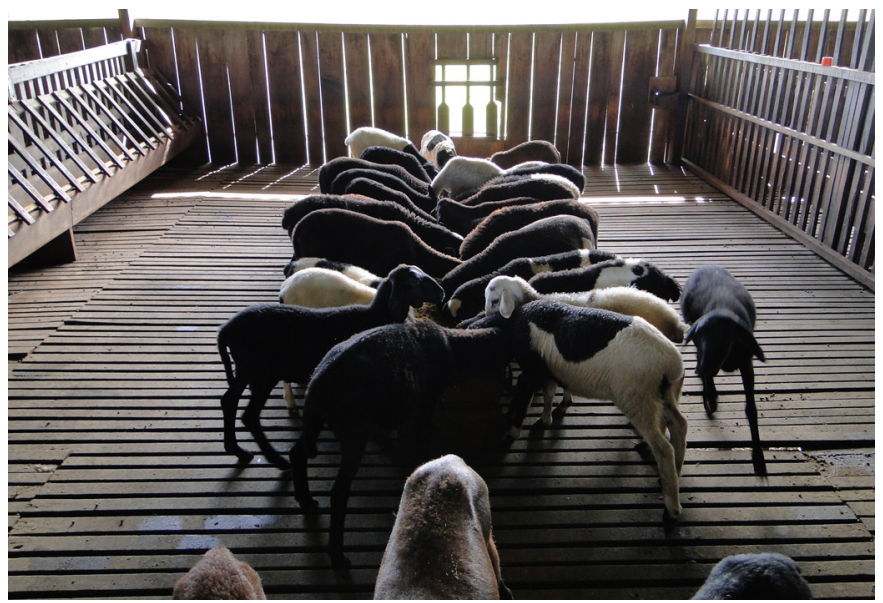

Fig.1. Intoxicação por sal em ovinos. No fundo da baia, a abertura de acesso ao bebedouro permite que apenas dois animais bebam ao mesmo tempo. purpureum) picado, que também era fornecido aos adultos, quando estabulados. Todos os animais recebiam mistura mineral (níveis de garantia/kg: Cálcio = mín. 220g, máx. $225 \mathrm{~g}$, fósforo $=$ mín. $75 \mathrm{~g}$, enxofre $=10 \mathrm{~g}$, magnésio $9 \mathrm{~g}$, sódio $=158 \mathrm{~g}$, ferro $=$ mín. $400 \mathrm{mg}$, zinco $=$ mín. $3.060 \mathrm{mg}$, iodo $=$ mín. 40mg, cobalto $=$ mín. $20 \mathrm{mg}$, vitamina $A=310.000 \mathrm{UI}$, vitamina D = mín. 50.000UI, vitamina E = mín. $435 \mathrm{UI}$, flúor = máx. $750 \mathrm{mg}$ ), fornecida em cochos de madeira medindo $18 \mathrm{~cm}$ de largura $\times 18 \mathrm{~cm}$ de comprimento $\mathrm{x} 10 \mathrm{~cm}$ de profundidade; as baias menores continham dois desses cochos e as maiores, quatro deles. Este fornecimento de mistura mineral ocasionalmente era interrompido pela falta do produto e os animais eram privados da mistura mineral durante alguns dias. Quando ela era oferecida novamente os animais disputavam espaço no cocho de sal e ingeriam a mistura avidamente. Isso foi constatado ao se colocarem $3 \mathrm{~kg}$ de mistura mineral para um lote de 37 animais e, no dia seguinte toda a mistura havia sido consumida (ingestão média de $81 \mathrm{~g} /$ animal). Todos os ovinos recebiam resíduo de cervejaria, com 3,3\% de sal mineral fornecido à vontade.

Oito animais adoeceram e quatro deles morreram. 0 grupo de animais doentes foi constituído por dois machos adultos da raça Dorper, três fêmeas adultas, duas da raça Santa Inês e uma mestiça, além de três ovinos jovens, sendo um macho e uma fêmea, ambos da raça Santa Inês e um macho mestiço. A taxa de morbidade foi de $1,46 \%$ e a de letalidade, de $50 \%$.

Os sinais clínicos compilados nos quadros 1 e 2, referiram-se principalmente aos sistemas nervoso e digestório, mas alterações dos sistemas respiratório, urinário e dos parâmetros do exame geral também foram observadas. Os sinais neurológicos mais frequentes foram diminuição ou ausência da sensibilidade cutânea (4/4), decúbito esternal (5/8) e lateral (4/8), midríase (3/6), ausência dos reflexos de ameaça (2/4), palpebral (2/2) e auricular (2/2), nistagmo $(3 / 8)$, opistótono $(3 / 8)$ e espasticidade de membros (3/8), alterações do estado mental como sonolência (2/8) e estupor (2/8), permanência em estação com a cabeça baixa (2/8) (Fig.2), tremores musculares (2/8), movimentos de pedalagem (2/8) e estrabismo dorsomedial (1/4) (Fig.3). Outros sinais neurológicos observados (1/8) foram andar rígido, instabilidade em estação e fraqueza muscular. As duas alterações relativas ao sistema respiratório foram taquipneia (6/8) e expiração dupla (1/8). 0 principal sinal referente ao sistema digestório foi timpanismo (3/8) e

Quadro 1. Intoxicação por sal em ovinos. Sinais clínicos relativos aos sistemas digestório, respiratório, urinário e outros parâmetros do exame geral

\begin{tabular}{|c|c|c|c|c|c|c|c|c|c|c|c|c|c|}
\hline Animal & $\begin{array}{l}\text { Hipomo- } \\
\text { tilidade } \\
\text { ruminal }\end{array}$ & $\begin{array}{l}\text { Timpa- } \\
\text { nismo }\end{array}$ & Diarreia & $\begin{array}{l}\text { Taqui- } \\
\text { pneia }\end{array}$ & $\begin{array}{c}\text { Expiração } \\
\text { dupla }\end{array}$ & $\begin{array}{c}\text { Taqui } \\
\text { cardia }\end{array}$ & $\begin{array}{c}\text { Mucosa } \\
\text { ocular } \\
\text { hiperêmica }\end{array}$ & $\begin{array}{l}\text { Micção- } \\
\text { frequente }\end{array}$ & $\begin{array}{c}\text { Diminuição } \\
\text { do turgor } \\
\text { cutâneo }\end{array}$ & Enoftalmia & $\begin{array}{c}\text { Dorso } \\
\text { arqueado }\end{array}$ & Hipertermia & Inquietação \\
\hline Ovino 1 & NA & + & - & + & - & NA & - & - & NA & - & - & NA & - \\
\hline Ovino 2 & NA & - & - & - & - & NA & - & + & NA & - & + & NA & - \\
\hline Ovino 3 & + & - & + & + & $\mathrm{P}$ & ++ & - & - & +++ & ++ & - & - & - \\
\hline Ovino 4 & NA & +++ & - & +++ & - & NA & - & - & NA & - & ++ & NA & + \\
\hline Ovino 5 & NA & - & - & - & - & ++ & - & - & NA & - & - & - & - \\
\hline Ovino 6 & NA & +++ & - & +++ & - & NA & - & ++ & NA & - & - & NA & - \\
\hline Ovino 7 & NA & - & - & +++ & - & NA & - & - & NA & - & - & NA & - \\
\hline Ovino 8 & NA & - & - & ++ & - & ++ & + & - & +++ & +++ & - & $\mathrm{P}$ & - \\
\hline
\end{tabular}

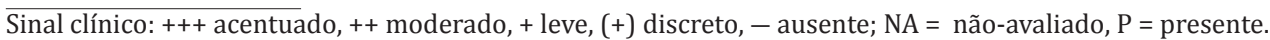




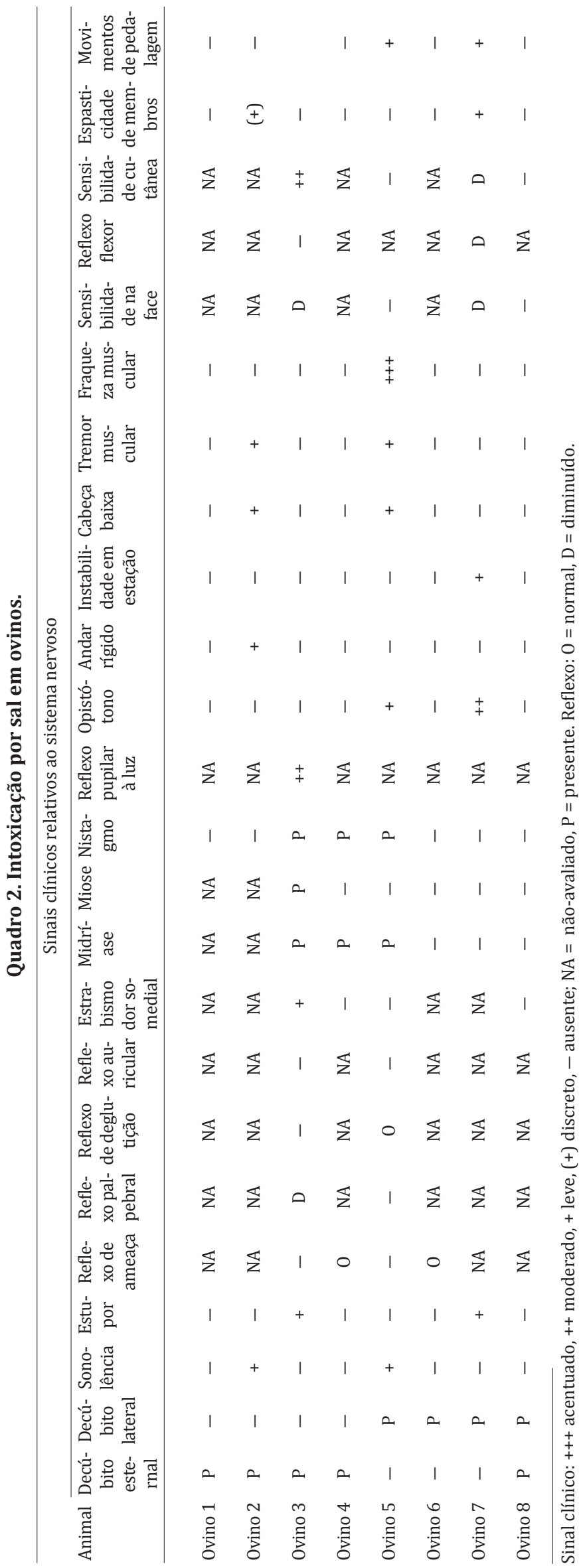

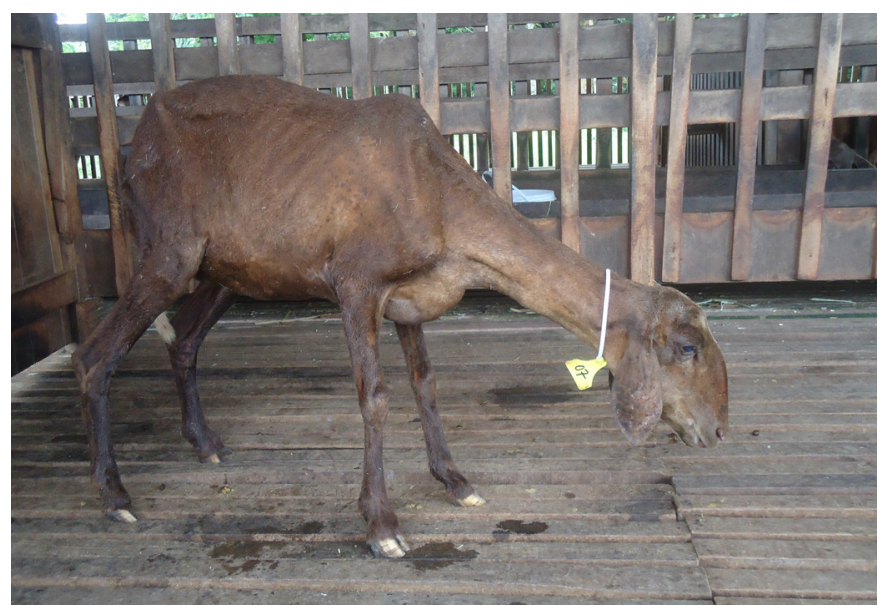

Fig.2. Intoxicação por sal em ovinos. Ovino 5 em estação com a cabeça baixa e os membros abduzidos.

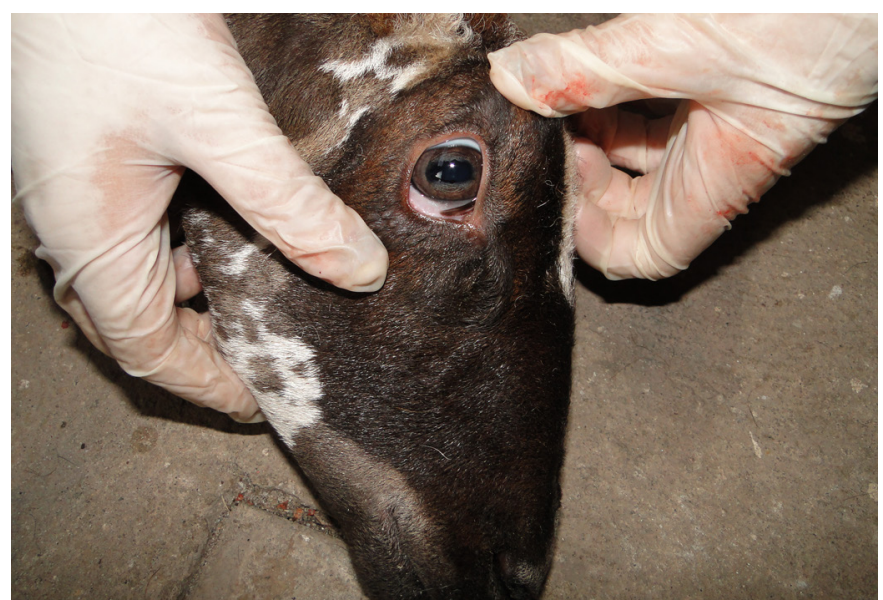

Fig.3. Intoxicação por sal em ovinos. Ovino 3 com estrabismo dorsomedial.

em um animal observou-se diarreia. Com relação ao sistema urinário o sinal observado foi micção frequente (2/8). Além disso, observaram-se taquicardia (3/3), hiperemia da mucosa ocular (1/8), diminuição do turgor cutâneo $(2 / 2)$, enoftalmia (2/8), dorso arqueado (2/8), hipertermia (1/3) e inquietação. A evolução do quadro clínico nos animais que morreram variou de 2 horas e meia a 48 horas. Nos animais que se recuperaram não foi possível determinar com exatidão o período de evolução do quadro clínico.

A média das concentrações séricas de sódio e de potássio de 31 ovinos do mesmo lote afetado pela intoxicação, em amostras colhidas durante o surto, foi de $190 \mathrm{mEq} / \mathrm{l} \mathrm{e}$ $8,2 \mathrm{mEq} / \mathrm{l}$ (quadro 3). A dosagem de sódio no encéfalo no ovino 8, revelou valor de 3.513ppm.

À necropsia, apenas no ovino 3 foi observada alteração, que consistiu de leve achatamento das circunvoluções cerebrais. Microscopicamente, este animal apresentou alterações que consistiram de vacuolização do neurópilo no córtex cerebral, de intensidade moderada nas lâminas intermediárias e leve na superficial, com aumento dos espaços perineural e perivascular. Os neurônios, nestas áreas, apresentavam acentuada retração citoplasmática com aumento da eosinofilia e núcleos picnóticos. Observaram-se 
ainda acentuada tumefação dos astrócitos que, por vezes, apresentavam evidenciação do citoplasma eosinofílico (Fig.4).

Quadro 3. Intoxicação por sal em ovinos. Dosagem sérica de sódio e potássio em amostras colhidas de ovinos clinicamente saudáveis, do mesmo lote e no mesmo período em que ocorreu a intoxicação

\begin{tabular}{|c|c|c|}
\hline Ovinos & $\begin{array}{c}\text { Dosagem de } \\
\text { sódio(mEq/l) }\end{array}$ & $\begin{array}{c}\text { Dosagem de } \\
\text { potássio }(\mathrm{mEq} / \mathrm{l})\end{array}$ \\
\hline 9 & 200 & 8,0 \\
\hline 10 & 200 & 8,8 \\
\hline 11 & 200 & 9,5 \\
\hline 12 & 168 & 6,0 \\
\hline 13 & 184 & 7,5 \\
\hline 14 & 146 & 4,9 \\
\hline 15 & 200 & 8,5 \\
\hline 16 & 148 & 5,2 \\
\hline 17 & 200 & 9,6 \\
\hline 18 & 199 & 8,4 \\
\hline 19 & 138 & 4,6 \\
\hline 20 & 190 & 8,8 \\
\hline 21 & 180 & 8,7 \\
\hline 22 & 200 & 8,7 \\
\hline 23 & 200 & 9,2 \\
\hline 24 & 200 & 8,4 \\
\hline 25 & 200 & 8,0 \\
\hline 26 & 188 & 10,0 \\
\hline 27 & 196 & 9,4 \\
\hline 28 & 200 & 9,2 \\
\hline 29 & 200 & 8,8 \\
\hline 30 & 200 & 7,8 \\
\hline 31 & 200 & 9,8 \\
\hline 32 & 196 & 7,2 \\
\hline 33 & 200 & 9,0 \\
\hline 34 & 200 & 9,7 \\
\hline 35 & 184 & 8,5 \\
\hline 36 & 180 & 7,4 \\
\hline 37 & 200 & 8,8 \\
\hline 38 & 200 & 9,0 \\
\hline 39 & 199 & 7,7 \\
\hline Média & 190 & 8,2 \\
\hline Valor de referência (mEq/la) & $139-152$ & $3,9-5,4$ \\
\hline
\end{tabular}

a Kaneco (2008).

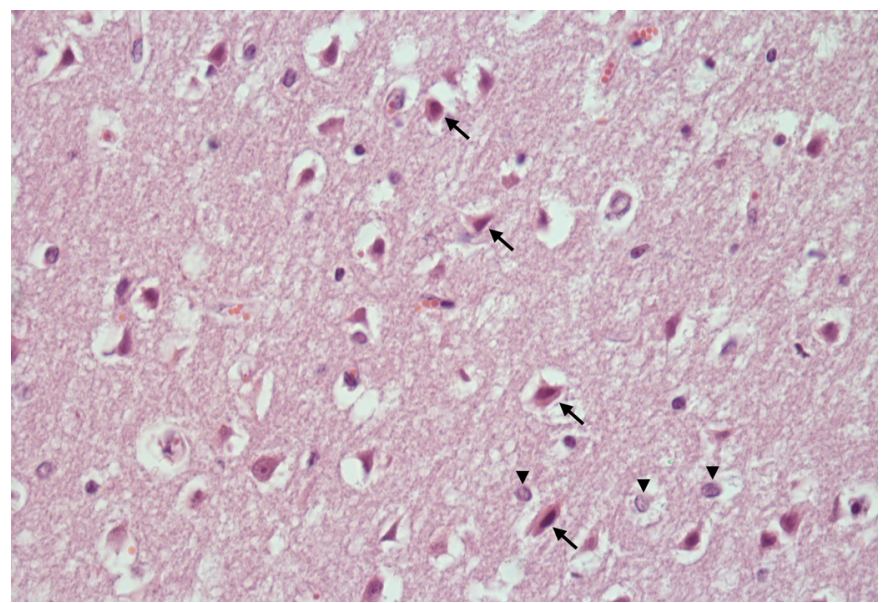

Fig.4. Intoxicação por sal em ovinos. Córtex cerebral. Neurônios retraídos, com aumento da eosinofilia citoplasmática, picnose (setas) e tumefação acentuada de astrócitos (cabeças de setas). HE, obj.40x.

\section{DISCUSSÃO}

O diagnóstico de intoxicação por sal nos casos do presente estudo foi baseado na epidemiologia, nos sinais clínicos (Moule 1945, Smith \& Fyfe 1971, Scarratt et al. 1985, Radostits et al. 2007), nas lesões macro e microscópicas (Summers et al. 1995) e nas dosagens de sódio no soro e no encéfalo (Thompson 2007).

A área disponível nas baias do aprisco, em torno de 0,5 $\mathrm{m}^{2}$ por animal adulto, era menor do que a recomendada, de 0,75 a $0,95 \mathrm{~m}^{2} /$ animal, para ovelhas e cabras secas (Turco \& Araújo 2011), o que demonstra que havia superlotação. Segundo Niles (2004) a superlotação é uma das causas de privação hídrica. Além disso, para um fornecimento hídrico ideal, o bebedouro deve ter tamanho que possibilite o acesso simultâneo de $10 \%$ do lote, sendo necessários $30 \mathrm{~cm}$ por animal (Depi 2014). No rebanho em questão, somente dois animais (aproximadamente 5\%), em lotes de aproximadamente 45, tinham acesso ao bebedouro simultaneamente. Estes dois fatores, a superlotação e o acesso limitado ao bebedouro, comprovam que houve restrição hídrica. Em grande parte dos relatos da intoxicação por sal em ruminantes, especialmente em ovinos, a privação hídrica foi um fator predisponente na epidemiologia da doença (Moule 1945, Smith \& Fyfe 1971, Lindley 1977, Trueman \& Clague 1978, Scarratt et al. 1985, Senturk \& Cihan 2004).

Outro aspecto importante na ocorrência da intoxicação por sal neste rebanho foi o excesso de ingestão da mistura mineral após períodos de interrupção do seu fornecimento. McDowell (1999) recomenda que os cálculos de misturas minerais para ovinos adultos sejam baseados em um consumo diário de $15 \mathrm{~g}$ de sal. Riet-Correa (2010), por sua vez, estima que esta ingestão deva ser de $10 \mathrm{~g}$ para ovinos de $30 \mathrm{~kg}$. A mistura mineral ingerida pelos animais que se intoxicaram continha $158 \mathrm{~g}$ de sódio/ $\mathrm{kg}$, o que corresponde a $427 \mathrm{~g}$ de cloreto de sódio/kg da mistura mineral. Considerando a ingestão média de $81 \mathrm{~g}$ da mistura mineral/animal, observada no fornecimento após a restrição do sal, cada ovino ingeriu, em média, 34,6g de cloreto de sódio, o que corresponde a duas ou três vezes mais do que os valores preconizados por McDowel (1999) ou Riet-Correa (2010), respectivamente. A intoxicação em bovinos foi observada após a ingestão de $75 \mathrm{~g}$ de cloreto de sódio, seguida por aproximadamente 34 horas de privação hídrica (Trueman \& Clague 1978), o que corresponde a 2,5 vezes o consumo estimado para bovinos adultos (Tokarnia et al. 2010). Além do consumo excessivo de sal por meio da mistura mineral, os ovinos deste surto recebiam resíduo de cervejaria contendo $3,3 \%$ de sal mineral, que correspondia a $1,42 \%$ de cloreto de sódio. Scarratt et al. (1985) relataram a intoxicação em ovinos após a ingestão de um suplemento mineral com $4 \%$ de cloreto de sódio associada à privação de água por 24 horas. Entretanto, a administração de cloreto de sódio a 4\% na ração é utilizada para o controle da urolitíase em carneiros castrados confinados e rações com até $13 \%$ de cloreto de sódio são fornecidas a ovelhas por longos períodos sem efeitos deletérios aparentes, desde que haja acesso livre à água (Radostits et al. 2007). Assim, a princípio, o excesso de sódio por si pode não ter sido a condição suficiente para causar a intoxicação por sal nos ovinos do presente estudo. 
Como mencionado na literatura (Scarratt et al. 1985, Trueman \& Clague 1978), a associação dos dois fatores provavelmente foi importante para o desenvolvimento da doença.

Os sinais clínicos observados nos ovinos deste surto foram semelhantes aos relatados em outros surtos de intoxicação por sal nesta espécie (Moule 1945, Smith \& Fyfe 1971, Scarratt et al. 1985) e em bovinos (Sandals 1978, Pringle \& Berthiaume 1988, Senturk \& Cihan 2005). Os sinais digestivos evidenciados neste surto ocorrem nas formas aguda e subaguda da intoxicação em ruminantes (Radostits et al. 2007). 0 timpanismo (Ovinos 1, 4 e 6) e a diarreia (Ovino 3) já descritos em bovinos intoxicados por sal (Ohman 1939, Sandals 1978, Pringle \& Berthiaume 1988, Van Leeuwen 1999, Senturk \& Cihan 2005), resultam dos efeitos irritantes da elevada concentração de sal no sistema digestório (Radostits et al. 2007), que adicionalmente produz diarreia por aumento da pressão osmótica no conteúdo intestinal (Smith 2006). Sinais nervosos como sonolência, estupor e ausência do reflexo de ameaça, observados neste estudo, têm sido descritos em doenças que cursam com edema cerebral (Mayhew 1989, De Lahunta \& Glass 2009). Outros sinais, também evidenciados nos ovinos deste surto, como diminuição ou ausência dos reflexos palpebral, de deglutição e auricular, estrabismo dorsomedial, diminuição ou ausência da sensibilidade cutânea na face, nistagmo, espasticidade de membros e opistótono têm sido atribuídos a compressão de outras estruturas encefálicas, como o tronco encefálico e o cerebelo, pelo edema cerebral (Mayhew 1989, Riet-Correa et al. 2002). Em um dos ovinos deste estudo este edema foi observado.

A micção frequente observada em dois animais deste estudo, já foi descrita na intoxicação aguda por sal em bovinos (Radostits et al. 2007) e provavelmente deve-se aos mecanismos de controle da osmolalidade e do volume plasmáticos. A hipernatremia provoca o aumento da ingestão de água, por estímulo da sede e retenção hídrica pelos rins, por meio da liberação de hormônio antidiurético (ADH) pela neurohipófise (Houpt 2006). A maior retenção de água reduz a osmolalidade, porém ocorre expansão do volume do fluido extracelular, que, por sua vez, inibe o sistema renina-angiotensina-aldosterona. Como a reabsorção direta de sódio no túbulo proximal e indireta pela ação da aldosterona estão bloqueadas, ocorre maior eliminação de sódio na urina e consequentemente de água. Além disso, na hipervolemia o estiramento de receptores no átrio esquerdo inicia um reflexo cujo ramo aferente situa-se nos nervos vagos. 0 ramo eferente deste reflexo provoca uma resposta para aumentar a diurese por meio da inibição da liberação de ADH e da supressão da atividade nervosa simpática renal, que aumentam a eliminação renal de água e sódio. Outro mecanismo que aumenta a eliminação renal de sódio é a liberação do peptídeo natriurético atrial pelas células miocárdicas estiradas durante a hipervolemia (Reece 2006).

A hipertermia, observada em um animal deste estudo, tem sido relatada por vários autores em surtos de intoxicação por sal (Smith \& Fyfe 1971, Pearson \& Kallfelz 1982, Scarratt et al. 1985, Senturk \& Cihan 2005). Segundo Radostits et al. (2007), no início da desidratação a temperatura corporal pode aumentar ligeiramente devido à quantidade diminuída de líquido para manter a perda de calor por evaporação, o que é conhecido como hipertermia da desidratação. Estes autores afirmam ainda que atividade muscular excessiva também pode causar hipertermia. Adicionalmente, distúrbios no hipotálamo, mais especificamente no centro de perda de calor, localizado na área hipotalâmica rostral podem causar hipertermia (De Lahunta \& Glass 2009).

A midríase verificada em três ovinos deste estudo não tem sido descrita nos animais intoxicados por sal, porém em seres humanos, este sinal já foi relatado (Degenaro \& Nyhan 1971). Distúrbios da contração pupilar comumente acompanham doenças agudas que afetam o prosencéfalo como a polioencefalomalácia por deficiência de tiamina e a intoxicação por chumbo. Nestes casos o reflexo pupilar à luz geralmente está preservado, porém nos casos em que ocorre herniação do lobo occipital sob o tentório, a compressão e o deslocamento do mesencéfalo ou do nervo oculomotor ou de ambos, provoca midríase sem reflexo pupilar à luz (De Lahunta \& Glass 2009).

A taxa de morbidade de 1,46\% verificada neste surto é menor do que as descritas por outros autores na intoxicação por sal em ovinos, que variaram de 6 a 10,5\% (Moule 1945, Smith \& Fyfe 1971, Scarratt 1985). Possivelmente isso ocorreu devido à restrição hídrica não ter sido total, com isso os mecanismos de controle puderam atuar de alguma forma e menos animais adoeceram. A taxa de letalidade de $50 \%$ foi semelhante à dos surtos descritos em ovinos (47,6 a 66,6\%) (Moule 1945, Smith \& Fyfe 1971, Scarratt 1985).

A média das concentrações séricas de sódio, em amostras obtidas durante o surto, de 31 ovinos do mesmo lote afetado pela intoxicação, foi de $190 \mathrm{mEq} / \mathrm{l}$. Esse valor está acima dos valores de referência para a espécie, que são de 139 a 152mEq/l (Kaneco 2008) e são semelhantes aos já descritos na intoxicação por sal em ovinos (Scarratt et al. 1985). Esses mesmos animais também revelaram níveis séricos de potássio superiores aos considerados normais para a espécie (3,9-5,4mEq/l) (Kaneco 2008), com uma média de 8,2mEq/l. Em condições normais a maior concentração de potássio está no interior da célula ao contrário da concentração de sódio que é maior no exterior, essa diferença é mantida pela bomba de sódio e potássio, que por sua vez depende de energia (Klein 2006). Como o excesso de sódio inibe a glicólise (Thompson 2007), provavelmente a concentração sérica de potássio aumentou devido ao não funcionamento da bomba de sódio e potássio. Além disso, a inibição do sistema renina-angiotensina-aldosterona causada pela hipernatremia pode ter diminuído a excreção renal de potássio, uma vez que esta é uma das funções da aldosterona (Eiler 2006).

0 achatamento das circunvoluções, observado em um animal deste surto (ovino 3), tem sido descrito na intoxicação por sal em suínos (Summers et al. 1995, Boos et al. 2012, Zachary 2013) e corresponde a edema cerebral (Cebra \& Cebra 2004, Maxie \& Youssef 2007).

A vacuolização do neurópilo e a necrose neuronal nas lâminas intermediárias do córtex cerebral, observadas microscopicamente no ovino 3, foram também descritas na 
intoxicação por sal em bovinos (Trueman \& Clague 1978). Em ovinos, Scarratt et al. (1985) descreveram moderado edema e necrose laminar nas camadas profundas do córtex cerebral. Lesões neuronais com estas características com frequência são associadas à necrose isquêmica (Maxie \& Youssef 2007). 0 Ovino 3 apresentou ainda, aumento dos espaços perineural e perivascular, além de acentuada tumefação do núcleo dos astrócitos que, por vezes, apresentavam citoplasma eosinofílico. Segundo Maxie \& Youssef (2007), alterações desta natureza indicam uma resposta astrocitária frente a lesões nos próprios astrócitos ou nas células que os circundam e estão frequentemente relacionadas ao edema citotóxico severo.

A dosagem de sódio no encéfalo do Ovino 8, resultou no valor de $3.513 \mathrm{ppm}$. Não existem dados na literatura sobre os níveis de sódio no encéfalo de ovinos clinicamente sadios. Entretanto, Thompson (2007) afirma que apesar da escassez de dados eles devem ser semelhantes aos valores de referência para bovinos (limite superior de $1.600 \mathrm{ppm}$ ). Este autor considera que concentrações de sódio acima de 2.000ppm são confirmatórias da intoxicação por sal em bovinos.

A forma aguda da intoxicação por sal em ovinos deve ser diferenciada de outras doenças que manifestam sinais clínicos de origem cerebral. A polioencefalomalácia associada à deficiência de tiamina e a polioencefalomalácia por excesso de enxofre são diferenciais importantes. Na primeira, o histórico costuma revelar mudança brusca na alimentação ou excesso de carboidratos de fácil digestibilidade, dados estes não mencionados no histórico do presente caso. Na segunda, os níveis de enxofre na alimentação geralmente estão acima de $0,4 \%$ e o aumento do sulfeto de hidrogênio na camada gasosa do rúmem nos outros animais do rebanho pode auxiliar na diferenciação. A intoxicação por chumbo, que também pode causar lesão de polioencefalomalácia, pode ser confirmada pela presença de inclusões intranucleares nos túbulos renais quando presentes, porém não observados nos casos descritos aqui e/ou da fonte tóxica e de altos níveis de chumbo no fígado e no rim. Na meningite difusa, nota-se alta celularidade no líquor e infiltrado neutrofílico nas meninges e espaços perivasculares, o que possibilita a diferenciação. A forma subaguda da enterotoxemia por Clostridium perfringens tipo D, denominada necrose simétrica focal, pode ser facilmente confirmada pela presença de lesões macro e microscópicas de malácia, simétricas na base do encéfalo. A intoxicação por closantel, que também causa sinais cerebrais, produz lesões histológicas características de espongiose na substância branca. Outras doenças que cursem com alterações digestivas, principalmente timpanismo e diarreia também devem ser diferenciadas da intoxicação por sal. Dentre elas destacam-se a acidose ruminal por excesso de carboidratos de fácil digestibilidade, que pode ser confirmada pelo exame do fluido ruminal, evidenciando $\mathrm{pH}$ abaixo de 5,0 e pelo histórico de aumento súbito na ingestão de carboidratos de fácil digestibilidade; à necropsia, quando o epitélio do rúmen é destacado, a lâmina própria apresenta áreas de hiperemia. A ingestão de leguminosas dos gêneros Trifolium e Medicago e de grãos também deve ser considerada, pois causam timpanismo es- pumoso. Neste caso, a constatação de timpanismo que não pode ser aliviado pela passagem de sonda, além da ausência de sinais nervosos proporciona a diferenciação.

$\mathrm{Na}$ profilaxia desta intoxicação, deve-se assegurar um fornecimento hídrico adequado, com bebedouros que possibilitem o acesso simultâneo a $10 \%$ da quantidade total de animais do lote. Além disso, após interrupções no fornecimento das misturas minerais, deve-se reintroduzi-las gradativamente para evitar consumo excessivo. Deve-se ainda evitar a adição de sal ao alimento concentrado, quando este já estiver disponível para consumo voluntário.

\section{CONCLUSÃO}

Com base nos dados epidemiológicos, nos sinais clínicos, nas alterações macro e microscópicas e nos achados toxicológicos, conclui-se que o rebanho ovino em questão apresentou intoxicação por sal, relacionada à associação de ingestão excessiva de sal e restrição hídrica. Este é o primeiro relato desta intoxicação em ovinos no Brasil.

Agradecimentos.- A Pró-Reitoria de Pesquisa e Pós Graduação da Universidade Federal do Pará (PROPESP-UFPA), pelo apoio financeiro.

\section{REFERÊNCIAS}

Boos G.S., Watanabe T.T.N., Almeida P.R., Oliveira L.G.S., Pavarini S.P., Zlotowski P. \& Driemeier D. 2012. Surto de intoxicação por sal em suínos em Santa Catarina. Pesq. Vet. Bras. 32(4):329-332.

Buronfosse F. 1998. Intoxication par le chlorure de sodium dans um élevage de chèvres. Le Point Veterinaire 29(numéro spécial):1345-1346.

Cebra C.K. \& Cebra M.L. 2004. Altered mentation caused by polioencephalomalacia, hypernatremia, and lead poisoning. Vet. Clin. Food Anim. 20:287-302

De Lahunta A. \& Glass E. 2009. Veterinary Neuroanatomy and Clinical Neurology. $3^{\text {rd }}$ ed. Saunders Elsevier. St Louis, Missouri. 540p.

Degenaro F. \& Nyhan W.L. 1971. Salt - a dangerous "anditote". J. Pediatrics 78(6):1048-1049.

Depi 2014. Water supply for stock containment areas. Department of Environment and Primary Industries. Victoria State Government. Disponível em <http://www.depi.vic.gov.au/agriculture-and-food/farmmanagement/managing-dams/water-supply-for-stock-containment-areas> Acesso em 2 abr. 2014

Eiler H. 2006. Glândulas endócrinas, p.577-622. In: Reece W.O. (Ed.), Dukes - Fisiologia dos Animais Domésticos. $12^{\mathfrak{a}}$ ed. Guanabara Koogan, Rio de Janeiro.

Houpt T.R. 2006. Água e eletrólitos, p.11-23. In: Reece W.O. (Ed.), Dukes Fisiologia dos Animais Domésticos. 12a ed. Guanabara Koogan, Rio de Janeiro.

Kaneko J.J. 2008. Clinical Biochemistry of Domestic Animals. $6^{\text {th }}$ ed. Academic Press, San Diego. 932p.

Klein B.G. 2006. Potenciais de membrana: Geração e condução dos sinais elétricos nos neurônios, p.717-731. In: Reece W.O. (Ed.), Dukes - Fisiologia dos Animais Domésticos. 12ª ed. Guanabara Koogan, Rio de Janeiro.

Lemos R.A.A., Nakazato L., Barros C.S.L., Gattas C.B.A. \& Bonilla R. 1997. Meningoencefalite eosinofílica em bovinos no Estado de Mato Grosso do Sul. Arqs Inst. Biológico, São Paulo, 64(Supl.):43.

Lindley W.H. 1977. Water deprivation in cattle. J. Am. Vet. Med. Assoc. 171:439-440.

Maxie M.G. \& Youssef S. 2007. Nervous system, p.281-457. In: Maxie M.G. (Ed.), Jubb, Kennedy and Palmer's Pathology of Domestic Animals. Vol.1. $5^{\text {th }}$ ed. Saunders Elsevier, Edinburgh.

Mayhew I.G. 1989. Large Animal Neurology: a handbook for veterinary clinicians. Lea and Febiger, Philadelphia. 380p. 
McDowell L.R. 1999. Minerais para ruminantes sob pastejo em regiões tropicais, enfatizando o Brasil. $3^{\underline{a}}$ ed. University of Florida, Gainesville. 92p.

Morton W.J.T. \& Simonds J.B. 1856. On the poisonous properties of brine. The Veterinarian 29:356-3.

Moule G.R. 1945. Salt poisoning in sheep following evaporation of saline water. Aust. Vet. J. 21:37-38.

Niles G. 2004. Metals and minerals. Sodium, p.218-229. In: Pumlee K. (Ed.), Clinical Veterinary Toxicology. Mosby, St Louis, Missouri.

Ohman A.F.S. 1939. Poisoning of cattle by saline bore water. Aust. Vet. J. 15:37-41.

Pearson E.G. \& Kallfelz F.A. 1982. A case of presumptive salt poisoning (water deprivation) in veal calves. Cornell Vet. 72:142-149.

Pringle J.K. \& Berthiaume L.M.M. 1988. Hypernatremia in calves. J. Vet. Intern. Med. 2:66-70.

Radostits O.M., Gay C.C., Hinchcliff K.W. \& Constable P.D. 2007. Diseases associated with inorganic and farm chemicals, p.1824-1826. In: Ibid. (Eds), Veterinary Medicine: a textbook of the diseases of cattle, horses, sheep, pigs and goats. $10^{\text {th }}$ ed. Saunders Elsevier, Edinburgh.

Reece W.O. 2006. Função renal nos mamíferos, p.67-96. In: Ibid. (Ed.),

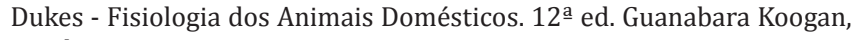
Rio de Janeiro.

Riet-Correa F., Riet-Correa G. \& Schild A.L. 2002. Importância do exame clínico para o diagnóstico das enfermidades do sistema nervoso em ruminantes e equídeos. Pesq. Vet. Bras. 22(4):161-168.

Riet-Correa F. 2010. Suplementação mineral em pequenos ruminantes, p.172-185. In: Tokarnia C.H., Peixoto P.V., Barbosa J.D., Brito M.F. \& Döbereiner J. (Eds), Deficiências Minerais em Animais de Produção. Editora Helianthus, Rio de Janeiro.

Sandals W.C.D. 1978. Acute salt poisoning in cattle. Can. Vet. J. 19:136-137. Scarratt W.K., Collins T.J. \& Sponenberg D.P. 1985. Water deprivation-so- dium chloride intoxication in a group of feeder lambs. J. Am. Vet. Med. Assoc. 186(9):977-978.

Senturk S. \& Cihan H. 2004. Salt poisoning in beef cattle. Vet. Human. Toxicol. 46(1):26-27.

Smith B. \& Fyfe B.H. 1971. Suspected acute salt poisoning in sheep. N. Z. Vet. J. 19:220-221.

Smith B.P. 2006. Intoxicação por sal, p.926-927. In: Ibid. (Ed.), Medicina Interna de Grandes Animais. $3^{\mathrm{a}}$ ed. Manole, Barueri.

Summers B.A., Cummings J. \& De Lahunta A. 1995. Degenerative diseases of the central nervous system: salt poisoning, p.254-255. In: Ibid. (Eds), Veterinary Neuropathology. Mosby, St Louis.

Thompson L.J. 2007. Sodium chloride (salt), p.461-464. In: Gupta R.C. (Ed.), Veterinary Toxicology: basic and clinical principles. Academic Press, New York.

Tokarnia C.H., Peixoto P.V., Barbosa J.D., Brito M.F. \& Döbereiner J. 2010. Deficiências Minerais em Animais de Produção. Editora, Helianthus, Rio de Janeiro. 200p.

Trueman K.F. \& Clague D.C. 1978. Sodium chloride poisoning in cattle. Aust. Vet. J. 54:89-91.

Turco S.H.N. \& Araujo G.G.L. 2011. Instalações, p.117-144. In: Voltolini T.V. (Ed.), Produção de Caprinos e Ovinos no Semiárido. Embrapa Semiárido, Petrolina.

Underwood E.J. \& Suttle N.F. 1999. Sodium and chlorine, p.185-212. In: Ibid. (Eds), The Mineral Nutrition of Livestock. $3^{\text {rd }}$ ed. CABI Publishing, Oxon.

Van Leeuwen J.A. 1999. Salt poisoning in beef cattle on costal pasture in Prince Edward lsland. Can. Vet. J. 40:347-348.

Zachary J.F. 2013. Sistema nervoso, p.774-873. In: Zachary J.F. \& McGavin M.D. (Eds), Bases da Patologia em Veterinária. 5aㅡ ed. Elsevier, Rio de Janeiro. 